\title{
Feasibility of the extracardiac conduit Fontan procedure in patients weighing less than 10 kilograms
}

\author{
Akio Ikai, MD, PhD, ${ }^{\text {a }}$ Yoshifumi Fujimoto, MD, ${ }^{\text {b }}$ Keiichi Hirose, MD, PhD, ${ }^{\text {b }}$ Noritaka Ota, MD, ${ }^{\text {b }}$ Yuko Tosaka, MD, ${ }^{\text {b }}$
} Tomohiro Nakata, MD, ${ }^{\mathrm{b}}$ Yujiro Ide, MD, ${ }^{\mathrm{b}}$ and Kisaburo Sakamoto, $\mathrm{MD}^{\mathrm{b}}$

Objective: The extracardiac conduit Fontan procedure has led to improved outcomes. We performed the procedure in patients weighing less than $10 \mathrm{~kg}$ and evaluated its feasibility.

Methods: Since January 1999, 72 patients weighing less than $20 \mathrm{~kg}$ underwent extracardiac conduit Fontan procedure with polytetrafluoroethylene conduits. The patients were divided into 2 groups: 36 patients weighing less than $10 \mathrm{~kg}$ in group $\mathrm{S}$ and 36 weighing more than $10 \mathrm{~kg}$ in group L. Mean weight, median age, and median follow-up period in groups $\mathrm{S}$ and $\mathrm{L}$ were $8.5 \pm 1.1$ and $14.0 \pm 3.0 \mathrm{~kg}, 18.9$ and 42.0 months, and 29.2 (1.7-79.7) and 42.1 (2.8-94.2) months, respectively. Postoperatively, most patients received peritoneal drainage catheters. We reviewed data precatheterization and postcatheterization and postoperative course.

Results: Conduit sizes in groups $\mathrm{S}$ and $\mathrm{L}$ were $17.0 \pm 1.3$ and $17.9 \pm 1.9 \mathrm{~mm}$, respectively $(P=.03)$. Five patients required fenestrations. There were 2 hospital deaths, 1 in each group, and 2 late deaths in group $\mathrm{S}$. The postoperative course was identical in both groups, except for median length of stay in the intensive care unit and peritoneal drainage volume. Group S versus L: ventilator support, 11 versus 7 hours; pleural drainage, 9 days each; pleural drainage greater than 14 days, 6 versus 5 cases; peritoneal drainage, 8 versus 7 days; intensive care unit stay, 7 versus 4 days $(P=.01)$, peritoneal drainage volume, 26.1 versus $14.1 \mathrm{~mL} \cdot \mathrm{kg} \cdot \mathrm{d}^{-1}(P=.0007)$.

Conclusions: The early outcome of the extracardiac conduit Fontan procedure was satisfactory in patients weighing less than $10 \mathrm{~kg}$. However, the required size of the conduit remains debatable.

From the Department of Cardiovascular Surgery, Iwate Medical University Memorial Heart Center, ${ }^{\mathrm{a}}$ and the Department of Cardiovascular Surgery, Shizuoka Children's Hospital, ' Shizuoka, Japan.

Read at the Thirty-third Annual Meeting of The Western Thoracic Surgical Association, Santa Ana Pueblo, NM, June 27-30, 2007.

Received for publication June 24, 2007; revisions received Dec 11, 2007; accepted for publication Dec 18, 2007.

Address for reprints: Kisaburo Sakamoto, MD, Department of Cardiovascular Surgery, Shizuoka Children's Hospital, 860 Urushiyama, Aoi-ku, Shizuoka 420-8505, Japan (E-mail: sakamoto@jun.ncvc.go.jp).

J Thorac Cardiovasc Surg 2008;135:114552

\section{$0022-5223 / \$ 34.00$}

Copyright (C) 2008 by The American Association for Thoracic Surgery

doi:10.1016/j.jtcvs.2007.12.013
T The current surgical goal for most patients with a functional single ventricle is staged palliation culminating in a successful Fontan procedure. Since its introduction in $1971,{ }^{1}$ the Fontan procedure has undergone many modifications. Currently, two modifications are commonly used - the lateral tunnel and extracardiac conduit Fontan procedures (LTFP and ECFP, respectively). ${ }^{2-4}$ The ECFP, introduced in $1990,{ }^{5}$ minimizes intratrial flow obstruction caused by intratrial partition. Moreover, the ECFP can be performed as a closed cardiac procedure without hypothermia, myocardial ischemia, or cardiopulmonary bypass. ${ }^{6}$ The hemodynamic advantages of a tubular Fontan pathway have been convincingly demonstrated by hydrodynamic and computational modeling studies. ${ }^{7,8}$ However, the ECFP has potential disadvantages related to the use of a prosthetic conduit, including the lack of growth potential, Fontan pathway obstruction, and thromboembolism. In particular, it is common practice to delay completion of Fontan circulation until the patient's body weight exceeds $15 \mathrm{~kg}$ to place an adult-sized conduit of at least $20 \mathrm{~mm}$ in diameter. ${ }^{9}$ However, one final treatment goal in patients with single ventricle physiology is the elimination of cyanosis. To eliminate cyanosis as early in life as possible, we therefore performed the ECFP in patients weighing less than $10 \mathrm{~kg}$ and evaluated the feasibility of this strategy. 


\section{Abbreviations and Acronyms}

ECFP = extracardiac conduit Fontan procedure

$\mathrm{ECMO}=$ extracorporeal membrane oxygenation

IVC = inferior vena cava

LTFP = lateral tunnel Fontan procedure

PTFE = polytetrafluoroethylene

\section{Patients and Methods}

This study was approved by the ethics committee of Shizuoka Children's Hospital, and informed consent was obtained from all patients' parents. From January 1997 to November 2006, 72 consecutive ECFPs were performed at Shizuoka Children's Hospital in patients weighing less than $20 \mathrm{~kg}$. During the same period, we performed a total of 152 ECFPs. To precisely evaluate the influence of body weight on the ECFP, we excluded 43 patients who weighed more than $20 \mathrm{~kg}, 18$ patients who had undergone direct anastomosis between the inferior vena cava (IVC) and the main pulmonary artery stump, 18 patients who had undergone the LTFP, and 1 patient who had undergone an intracardiac conduit Fontan procedure. The remaining 72 patients were divided as follows into 2 equal groups on the basis of body weight: 36 patients weighing less than $10 \mathrm{~kg}$ (group S) and 36 weighing more than $10 \mathrm{~kg}$ (group L). Cardiac catheterization was performed in the midterm postoperative period at approximately 1 year after the operation. Follow-up was complete in all patients.

\section{Surgical Techniques}

All the ECFPs were performed via a median sternotomy and with cardiopulmonary bypass. Aortic crossclamping was used in 41 patients, including 17 (47\%) group S and 24 (67\%) group L patients. In crossclamped patients, myocardial protection was achieved with antegrade cold crystalloid cardioplegia. In small patients, the pulmonary artery incision was extended into the anterior wall of the superior vena cava to obtain enough space for anastomosis. As a conduit, we used polytetrafluoroethylene (PTFE; Gore-Tex; W. L. Gore \& Associates, Inc, Flagstaff, Ariz) of 14 to $20 \mathrm{~mm}$ in diameter. Modified ultrafiltration was used in all patients. Fenestrations were not initially placed. In patients in whom Fontan pressure greater than $18 \mathrm{~mm} \mathrm{Hg}$ developed after modified ultrafiltration, a fenestration was placed by interposing a small PTFE graft 4 or $5 \mathrm{~mm}$ in diameter between the conduit and the atrium.

A total of 69 patients had undergone previous procedures. Newly developed intrapulmonary artery septation procedures, ${ }^{10}$ which consist of unilateral cavopulmonary anastomosis, aortopulmonary shunt, and septation between two blood sources, were applied in both patient groups to promote growth in small pulmonary arteries.

The following procedures were concomitantly performed in 41 patients (17 group S and 24 group L patients): atrioventricular valve repair, branch pulmonary artery stenosis repair, atrial septectomy, main pulmonary artery division, pulmonary vein repair, DamusKaye-Stansel anastomosis, subaortic stenosis repair, and pacemaker-related procedures (see Table 3).

\section{TABLE 1. Preoperative patient profiles and cardiac catheterization data}

\begin{tabular}{|c|c|c|c|c|c|c|c|}
\hline & Group S & & & Group L & & & $P$ value \\
\hline \multicolumn{8}{|l|}{ Age (mo) } \\
\hline Mean & $21.0 \pm 8.7$ & & & $54.7 \pm 32.9$ & & & \\
\hline Median & $18.9(10.6-45.0)$ & & & $42.0(16.9-151.3)$ & & & $<.0001$ \\
\hline \multicolumn{8}{|l|}{ Weight (kg) } \\
\hline Mean & $8.5 \pm 1.1$ & & & $14.0 \pm 3.0$ & & & \\
\hline Median & $8.7(5.7-10.2)$ & & & $13.9(10.3-19.8)$ & & & $<.0001$ \\
\hline \multicolumn{8}{|l|}{ Anatomic diagnosis } \\
\hline & No. & $\%$ & & No. & $\%$ & & \\
\hline HLHS & 11 & 31 & & 3 & 8 & & .03 \\
\hline Isomerism/heterotaxy & 10 & 28 & & 15 & 42 & & .38 \\
\hline Univentricular heart & 6 & 17 & & 7 & 19 & & .59 \\
\hline Tricuspid atresia & 2 & 6 & & 2 & 6 & & .999 \\
\hline Common atrioventricular canal & 1 & 3 & & 3 & 8 & & .33 \\
\hline DORV & 1 & 3 & & 3 & 8 & & .33 \\
\hline PA/IVS & 2 & 6 & & 0 & 0 & & .16 \\
\hline Other & 3 & 8 & & 3 & 8 & & \\
\hline Total & 36 & & & 36 & & & \\
\hline Preoperative data & & & $\mathrm{n}$ & & & $\mathrm{n}$ & \\
\hline PA pressure, mean $(\mathrm{mm} \mathrm{Hg})$ & $13 \pm 3$ & & 31 & $12 \pm 2$ & & 29 & .62 \\
\hline Atrial pressure, mean $(\mathrm{mm} \mathrm{Hg})$ & $7 \pm 3$ & & 36 & $7 \pm 2$ & & 36 & .25 \\
\hline Room air saturation (\%) & $85 \pm 4$ & & 33 & $85 \pm 5$ & & 36 & .38 \\
\hline Rp (Wood units) & $2.0 \pm 1.0$ & & 24 & $1.5 \pm 0.8$ & & 32 & .06 \\
\hline Ejection fraction (\%) & $58 \pm 10$ & & 35 & $57 \pm 11$ & & 34 & .42 \\
\hline Nakata index & $247 \pm 122$ & & 34 & $250 \pm 127$ & & 31 & .84 \\
\hline
\end{tabular}

HLHS, Hypoplastic left heart syndrome; DORV, double-outlet right ventricle; $P A / I V S$, pulmonary atresia with intact ventricular septum; $P A$, pulmonary artery; $R p$, resistance of pulmonary artery. 
Bilateral pleural drainage tubes were placed in all patients and removed when a drainage volume of less than $1 \mathrm{~mL} \cdot \mathrm{kg} \cdot \mathrm{d}^{-1}$ was achieved in each tube. Peritoneal drainage tubes were regularly used to remove peritoneal fluid and to reduce intraperitoneal pressure; they were removed when a drainage volume of less than $2 \mathrm{~mL}$. $\mathrm{kg} \cdot \mathrm{d}^{-1}$ was achieved. In both patient groups, we routinely administered $5 \mathrm{mg} / \mathrm{kg}$ ticlopidine as antiplatelet therapy. Warfarin was not used.

\section{Statistics}

Data from groups were compared by the unpaired Student $t$ test, Fisher exact test, or $\chi^{2}$ test, as appropriate. Serial data from postoperative catheterization were compared by the paired Student $t$ test. Data are shown as mean \pm standard deviation or median (range). The Kaplan-Meier method was used to determine the time from surgery to death or the last follow-up visit.

\section{Results}

The preoperative age and body weight of patients in group $S$ were significantly lower than in group L (Table 1). The number of patients having the morphologic features of hypoplastic left heart syndrome was higher in group $\mathrm{S}$ than in group $\mathrm{L}$ (group $\mathrm{S}$ vs group L: $11 \mathrm{vs} 3 ; P=.03$ ). Half of the patients in both groups had either hypoplastic left heart syndrome or heterotaxy syndrome. All patients underwent cardiac catheterization before ECFP. The mean values of the variables measured at catheterization were essentially identical in both groups. Pulmonary artery resistance was slightly higher in group $\mathrm{S}$ than in group L, but without significant difference (Table 1).

Only 3 of the 72 patients underwent the ECFP as a primary procedure. Further, 10 patients underwent ECFP without previous cavopulmonary connection. The remaining 59 patients had an interim cavopulmonary connection as a staging procedure, including 14 patients with intrapulmonary artery septation, 1 patient with a hemi-Fontan procedure, and 1 patient with a Kawashima procedure (Table 2). Other operations conducted previously are listed in Table 2. A significantly greater number of group $\mathrm{S}$ patients had previously undergone the Norwood procedures ( $36 \%$ vs $8 \%$ ), whereas group L patients had more frequently undergone isolated aortopulmonary or ventricular-pulmonary shunt procedures. Neither the mean cardiopulmonary bypass time nor the mean crossclamp time differed between the 2 groups. Fenestrations were placed in 3 group $\mathrm{S}$ and 2 group $\mathrm{L}$ patients. The size of the conduit used in group $\mathrm{S}$ was significantly smaller than that used in group L $(17.0 \pm 1.3 \mathrm{~mm}$ vs $17.9 \pm 1.9 \mathrm{~mm}$; $P=.03$ ) (Table 3). However, we have recently used $18-\mathrm{mm}$ conduits in an increasing number of group S patients (Figure 1).

\section{Early Outcome}

The overall operative mortality was $2(2.8 \%)$ of 72 patients. One group $\mathrm{S}$ patient with heterotaxy syndrome who had concomitantly undergone atrioventricular valve replacement died
TABLE 2. Previous procedures

\begin{tabular}{|c|c|c|}
\hline Previous procedures & Group S & Group L \\
\hline None & 2 & 1 \\
\hline \multicolumn{3}{|l|}{ C-P anastomosis } \\
\hline SVC-PA anastomosis & 23 & 22 \\
\hline Other & 1 & 0 \\
\hline Hemi-Fontan & 0 & 1 \\
\hline Kawashima & 0 & 1 \\
\hline Intrapulmonary artery septation & 6 & 8 \\
\hline None & 6 & 4 \\
\hline AV valve repair & 11 & 11 \\
\hline Pulmonary artery plasty & 23 & 27 \\
\hline Pulmonary artery banding & 9 & 16 \\
\hline Atrial septectomy & 8 & 3 \\
\hline DKS anastomosis & 4 & 2 \\
\hline Modified Norwood & 13 & 3 \\
\hline RV-PA conduit & 9 & 2 \\
\hline AP shunt & 4 & 1 \\
\hline AP shunt & 22 & 35 \\
\hline VP shunt & 0 & 5 \\
\hline TAPVC repair & 4 & 2 \\
\hline Coarctation repair & 2 & 7 \\
\hline Pacemaker implantation & 1 & 1 \\
\hline Pulmonary vein stenosis repair & 5 & 7 \\
\hline Starnes operation & 0 & 1 \\
\hline Diaphragm plication & 0 & 1 \\
\hline MAPCA unifocalization & 0 & 1 \\
\hline Aortic valve repair & 0 & 1 \\
\hline Aortic valve replacement & 0 & 1 \\
\hline AV valve replacement & 0 & 1 \\
\hline LV volume reduction surgery & 0 & 1 \\
\hline
\end{tabular}

C-P, Cavopulmonary; $S V C$, superior vena cava; $P A$, pulmonary artery; $A V$, atrioventricular; $D K S$, Damus-Kaye-Stansel; $A P$, aortopulmonary; $V P$, ventricular-pulmonary; TAPVC, total anomalous pulmonary venous connection; $M A P C A$, major aortopulmonary collateral arteries; $L V$, left ventricle.

of contractile dysfunction resulting from supraventricular tachycardia. A group L patient who had heterotaxy syndrome without fenestration died of cerebral embolism. Extracorporeal membrane oxygenation (ECMO) was used in 2 group $\mathrm{S}$ patients. A patient with pulmonary atresia with intact ventricular septum, who had sinusoidal communication had hemodynamic instability owing to coronary malperfusion. The patient was supported by ECMO for 3 days and survived. Another patient with the heterotaxy syndrome and pulmonary vein stenosis, who had previously undergone repair of total anomalous pulmonary venous connection followed by atrioventricular valve repair as a concomitant procedure, had respiratory dysfunction and elevation of Fontan pressure on postoperative day 2. The patient was supported with ECMO for 5 days and successfully weaned after fenestration. No significant difference was observed between the groups with regard to the duration of ventilator support, pleural drainage, and peritoneal drainage. The number of patients requiring prolonged pleural drainage for more than 14 days was not 
TABLE 3. Operative data

\begin{tabular}{|c|c|c|c|c|c|}
\hline & Group S & n & Group L & $\mathbf{n}$ & $P$ value \\
\hline Mean CPB time (min) & $147 \pm 54$ & & $167 \pm 53$ & & .09 \\
\hline Median & $136(67-282)$ & & $162(80-303)$ & & \\
\hline Aortic crossclamping, $\mathrm{n}(\%)$ & $17(47 \%)$ & & $24(67 \%)$ & & .38 \\
\hline Time (min) & $58 \pm 26$ & 17 & $69 \pm 35$ & 24 & .3 \\
\hline Median & $62(9-118)$ & & $63(10-134)$ & & \\
\hline Fenstration, n (\%) & $3(8 \%)$ & & $2(6 \%)$ & & .67 \\
\hline Mean graft size & $17.0 \pm 1.3$ & & $17.9 \pm 1.9$ & & $.03^{*}$ \\
\hline Median & $16(16-20)$ & & $18(14-20)$ & & \\
\hline \multicolumn{6}{|l|}{ Concomitant procedures } \\
\hline Intracardiac & & 8 & & 11 & .38 \\
\hline AV valve repair & 2 & & 4 & & \\
\hline ASD enlargement & 3 & & 3 & & \\
\hline$A V$ valve replacement & 1 & & 0 & & \\
\hline PVO repair & 0 & & 2 & & \\
\hline DKS anastomosis & 0 & & 1 & & \\
\hline SAS resection & 0 & & 1 & & \\
\hline PAPVC repair & 1 & & 0 & & \\
\hline PA-LA fistula closure & 1 & & 0 & & \\
\hline Extracardiac & & 9 & & 13 & .46 \\
\hline PA plasty & 6 & & 8 & & \\
\hline Main PA division & 0 & & 3 & & \\
\hline Pacemaker implantation & 1 & & 2 & & \\
\hline Other & 2 & & & & \\
\hline
\end{tabular}

$C P B$, Cardiopulmonary bypass; $A V$, atrioventricular; $A S D$, atrial septal defect; $P V O$, pulmonary vein obstruction; $D K S$, Damus-Kaye-Stansel; $S A S$, subaortic stenosis; $P A P V C$, partial anomalous pulmonary vein connection; $P A$, pulmonary artery; $L A$, left atrium. ${ }^{*} P<.05$ indicates significant $P$ value.

different between the groups (group S vs group L: 6 vs $5 ; P=$ .76). However, the median duration of stay in the intensive care unit was significantly longer for group $\mathrm{S}$ patients than for group L patients (group S vs L: 7 days vs 4 days; $P=$ 0.01 ), and the average volume of peritoneal drainage was significantly greater in group $\mathrm{S}$ than in group L (group S vs group

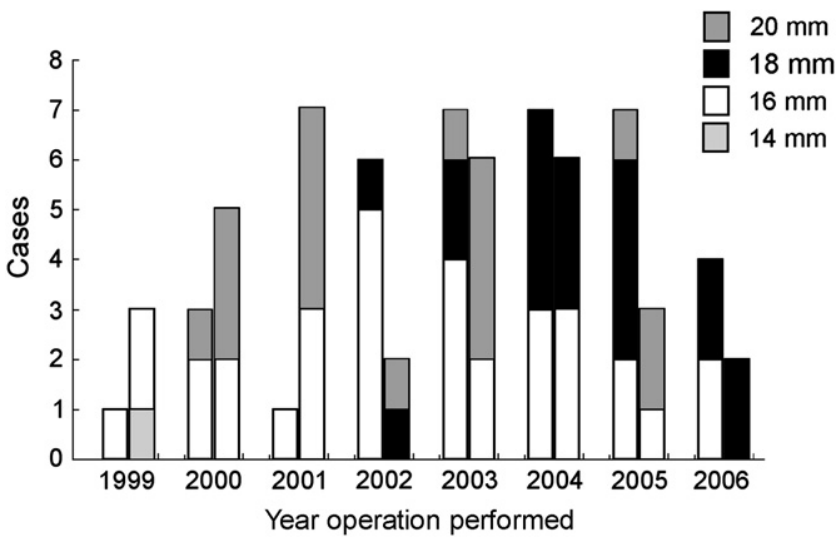

Figure 1. Distribution of the size of extracardiac conduit in 72 patients for each year. The left bar indicates cases in group $S$ and the right bar, in group $\mathrm{L}$. The dotted bar indicates a 14-mm diameter conduit; white bar, a 16-mm diameter conduit; black bar, an 18-mm diameter conduit; and gray bar, a 20-mm diameter conduit. Since 2002, use of 18-mm diameter conduits has increased.
$\mathrm{L}: 26.1 \pm 15.1 \mathrm{~mL} \cdot \mathrm{kg} \cdot \mathrm{d}^{-1} \mathrm{vs} 14.1 \pm 10.2 \mathrm{~mL} \cdot \mathrm{kg} \cdot \mathrm{d}^{-1}$; $P=.0007$ ) (Table 4). With regard to the prevalence of supraventricular dysrhythmia, 7 patients in group $S$ and 9 patients in group L had supraventricular tachyarrhythmia. Three patients in both groups had sinus dysfunction. There was no difference in the prevalence of supraventricular dysrhythmia between the 2 groups.

\section{Follow-up}

Follow-up was complete in all patients. Median follow-up periods were $29.2(1.7-79.7)$ and 42.1 (2.8-94.2) months for groups $\mathrm{S}$ and $\mathrm{L}$, respectively. Two group $\mathrm{S}$ patients with hypoplastic left heart and heterotaxy syndrome died of respiratory infection. The 5-year actuarial survival was $91 \%$ for group $\mathrm{S}$ and $97 \%$ for group L $(P=.3$, Figure 2$)$. Protein-losing enteropathy developed in 3 patients (2 in group $\mathrm{S}$ and 1 in group L). All patients are currently responding to medical treatment. Postoperatively, no thromboembolic events occurred, and no patient required conduit replacement for obstruction. With regard to the prevalence of supraventricular dysrhythmia, patients with sick sinus syndrome, and grade I atrioventricular block, 1 in each group were treated with a pacemaker to maintain better synchronicity between the atrial and ventricular contractions. Only 1 patient with heterotaxy syndrome in group $\mathrm{S}$ had supraventricular tachyarrhythmia even though the patient was 


\begin{tabular}{|c|c|c|c|c|c|}
\hline & Group S & $\mathbf{n}$ & Group L & $\mathbf{n}$ & $P$ value \\
\hline ICU stay, median (d) excluding death & $7(1-45)$ & 35 & $4(1-14)$ & 35 & $.01^{*}$ \\
\hline Hospital stay, median (d) excluding death & $31(13-85)$ & 35 & $28(17-143)$ & 35 & .53 \\
\hline Duration of ventilator support, median (h) & $11(3-1119)$ & 35 & 7 (3-1385) & 35 & .41 \\
\hline Duration of pleural drainage, median (d) & $9(5-27)$ & 34 & $9(5-19)$ & 34 & 69 \\
\hline Volume of pleural drainage, mean $\left(\mathrm{mL} \cdot \mathrm{kg} \cdot \mathrm{d}^{-1}\right)$ & $12.6 \pm 9.6$ & & $10.5 \pm 6.3$ & & .70 \\
\hline Prolonged pleural drainage $>14$ days (cases) & $6(16.7 \%)$ & & $5(14.7 \%)$ & & .78 \\
\hline Duration of peritoneal drainage, median (d) & $8(3-19)$ & 33 & $7(2-35)$ & 33 & .68 \\
\hline Volume of peritoneal drainage, mean $\left(\mathrm{mL} \cdot \mathrm{kg} \cdot \mathrm{d}^{-1}\right)$ & $26.1 \pm 15.1$ & & $14.1 \pm 10.2$ & & $.0007^{*}$ \\
\hline Prolonged peritoneal drainage $>14$ days (cases) & $2(6.1 \%)$ & & $3(9.1 \%)$ & & .67 \\
\hline
\end{tabular}

$I C U$, intensive care unit. ${ }^{*} P<.05$, indicates significant $P$ value.

administered amiodarone prophylactically. One patient in group L was administered isoproterenol owing to atrioventricular dissociation. With regard to fenestration, 1 patient who underwent fenestration in group $\mathrm{S}$ died of respiratory infection as previously mentioned. We confirmed spontaneous closure of the fenestration in 2 patients in group L. The other two fenestrations were left open.

\section{Follow-up Catheterization Data}

We performed postoperative follow-up catheterization in 30 group $\mathrm{S}$ and 32 group $\mathrm{L}$ patients. The mean interval between the ECFP and follow-up was $9.8 \pm 3.8$ months for group $\mathrm{S}$ and $13.1 \pm 4.2$ months in group L. There was a significant difference between these 2 periods $(P=.002)$.

No difference was observed between the groups with regard to IVC pressure, intraconduit pressure, superior vena cava pressure, bilateral pulmonary artery pressure, pulmonary capillary wedge pressure, pulmonary artery resistance, ejection fraction, cardiac index, and room air saturation (Table 5). There was a pressure gradient between precavopulmonary and postcavopulmonary anastomosis and there was also a statistically significant difference between the intra-

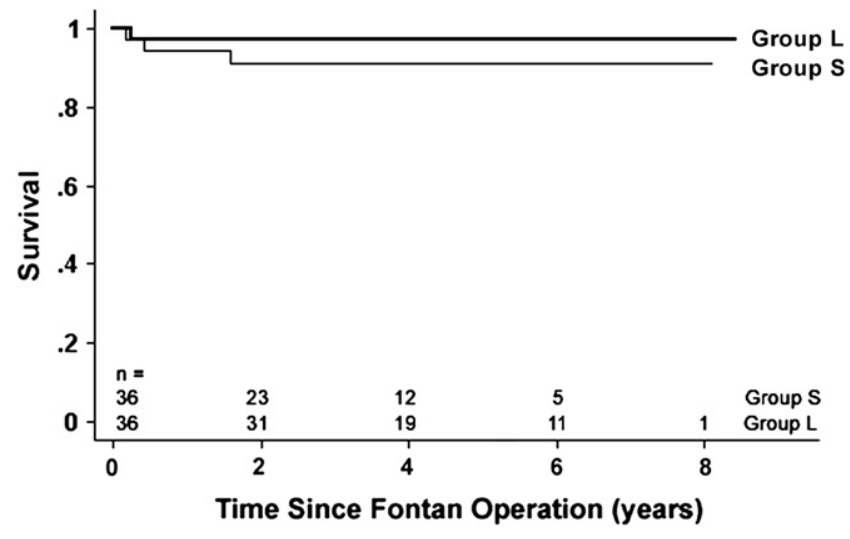

Figure 2. Kaplan-Meier survival in 72 patients undergoing the ECFP. The number of patients at risk is indicated above the horizontal axis. There is no difference of survival between patients in groups $S$ and $L$. conduit pressure and the right and left pulmonary artery pressures; however, no pressure gradient had developed between the IVC and conduit.

\section{Discussion}

Since the introduction of the concept of total cavopulmonary connection, ${ }^{7}$ the outcome of the Fontan completion has improved dramatically. Currently, the ECFP and LTFP are the two favored approaches for Fontan completion. However, the use of ECFP may be disadvantageous because of the use of an artificial graft that lacks growth potential and requires anticoagulation therapy to prevent thromboembolic events. ${ }^{9,11}$ Generally, ECFP is performed in patients weighing more than $15 \mathrm{~kg}$ so that an adult-sized conduit (generally $20 \mathrm{~mm}$ in diameter) can be used. Therefore, the patient age required for the ECFP is higher than that required for the LTFP. ${ }^{2-4}$ The data on the $\mathrm{LTFP}^{12}$ revealed that age at the time of operation was not a limiting factor for Fontan completion.

To eliminate cyanosis as early in life as possible, we performed the ECFP in patients who were approximately 1 year old and weighed less than $10 \mathrm{~kg}$. The operative mortality of the entire cohort of patients in this series was approximately $3 \%$. This is similar to that reported in previous studies. $2,6,13,14$ Numerous perioperative risk factors are associated with increased mortality after the ECFP. These include pulmonary artery resistance, pulmonary artery size, hypoplastic left heart syndrome, and heterotaxy syndrome. A direct comparison of the preoperative features of both patient groups revealed no differences in this study. In terms of morphologic features, especially, half of the patients in both the groups had hypoplastic left heart or heterotaxy syndrome. Moreover, pulmonary vascular resistance and Nakata index did not differ between the groups. Under well-controlled hemodynamic conditions for Fontan completion, the somatic size of patients might not be a limiting factor for performing the ECFP, even in patients weighing less than $10 \mathrm{~kg}$.

However, for performing ECFP in patients with low body weight, the size of the conduit, which lacks growth potential, might pose difficulties in the future. ${ }^{9,11}$ The main problem 
TABLE 5. Postoperative catheterization data

\begin{tabular}{|c|c|c|c|c|c|}
\hline & Group S & $\mathbf{n}$ & Group L & $\mathbf{n}$ & $P$ value \\
\hline Mean interval after ECFP (mo) & $9.8 \pm 3.8$ & 30 & $13.1 \pm 4.2$ & 32 & $.002^{*}$ \\
\hline SVC pressure, mean $(\mathrm{mm} \mathrm{Hg})$ & $12.4 \pm 2.4$ & 27 & $12.4 \pm 2.2$ & 29 & .94 \\
\hline Right PA pressure, mean $(\mathrm{mm} \mathrm{Hg})$ & $11.0 \pm 2.7 \dagger$ & 26 & $11.1 \pm 2.7 \dagger$ & 26 & .72 \\
\hline Left PA pressure, mean $(\mathrm{mm} \mathrm{Hg})$ & $11.0 \pm 2.6 \dagger$ & 26 & $10.9 \pm 2.7 \dagger$ & 29 & .92 \\
\hline Intraconduit pressure, mean $(\mathrm{mm} \mathrm{Hg})$ & $12.5 \pm 2.3$ & 21 & $12.2 \pm 2.2$ & 22 & .62 \\
\hline IVC pressure, mean $(\mathrm{mm} \mathrm{Hg})$ & $12.4 \pm 2.2$ & 28 & $12.4 \pm 2.1$ & 28 & .73 \\
\hline PCW pressure, mean (mm Hg) & $6 \pm 2$ & 29 & $6 \pm 3$ & 32 & .81 \\
\hline Rp (Wood units) & $1.7 \pm 1.0$ & 28 & $1.5 \pm 1.0$ & 29 & .38 \\
\hline Ejection fraction $(\%)$ & $54 \pm 11$ & 28 & $58 \pm 10$ & 32 & .15 \\
\hline Cardiac index $\left(\mathrm{L} / \mathrm{min} / \mathrm{m}^{2}\right)$ & $3.0 \pm 0.5$ & 28 & $3.2 \pm 1.1$ & 31 & .53 \\
\hline Room air saturation (\%) & $93 \pm 4$ & 28 & $95 \pm 1$ & 32 & .73 \\
\hline
\end{tabular}

$E C F$, Extracardiac conduit Fontan procedure; $S V C$, superior vena cava; $P A$, pulmonary artery; $I V C$, inferior vena cava; $P C W$, pulmonary capillary wedge; $R p$, resistance of pulmonary artery. ${ }^{*} P<.05$ significant $P$ value. $\dagger P<.05$ significant $P$ value; PA pressure versus SVC pressure, IVC pressure, and intraconduit pressure.

concerning ECFP is the risk of late conduit obstruction. Amodeo and colleagues ${ }^{15}$ have reported a mean reduction of the internal conduit diameter of $18 \%$ during the first 6 months with no further progression over the following 5 years. Marcelletti, Iorio, and Abella ${ }^{11}$ from the same study group reported that they had never used a conduit less than $16 \mathrm{~mm}$ in diameter in their initial series. However, no cases of PTFE conduit replacement owing to obstruction were reported in the longest follow-up series. There have been numerous reports regarding the benefits of ECFP; however, no reports of conduit replacement owing to size mismatch affecting somatic development have been reported. Nakao and colleagues ${ }^{16}$ have assessed the size of the IVC by means of echocardiography. In their study, mean diameters of the IVC were changed $17 \mathrm{~mm}$ in the left lateral position to 23 $\mathrm{mm}$ in the right lateral position in patients with right atrial pressures greater than $8 \mathrm{~mm} \mathrm{Hg}$. The study might suggest that a conduit 18 or $20 \mathrm{~mm}$ in diameter might be acceptable in adults. Initially, we used a conduit $16 \mathrm{~mm}$ in diameter; however, after gaining experience, we have recently increased the use of 18-mm diameter conduits. We administered $5 \mathrm{mg} / \mathrm{kg}$ of ticlopidine as antiplatelet therapy. We have not encountered any cases of conduit obstruction thus far; however, further studies are necessary for evaluating the fate of artificial tube grafts, particularly those less than $16 \mathrm{~mm}$ in diameter.

Persistent pleural effusion is one of the significant causes of morbidity in the postoperative period after ECFP. ${ }^{17}$ Gaynor and colleagues ${ }^{13}$ reported that fenestration and modified ultrafiltration are associated with a decrease in the duration of pleural effusions. In this series, we used modified ultrafiltration in all patients. Patients with fenestrations had to have cyanosis for a longer duration and had to undergo another intervention to close the fenestration. Therefore, we did not use fenestrations except in patients with a high Fontan pressure greater than $18 \mathrm{~mm} \mathrm{Hg}$. Only 5 (7\%) of 72 patients in this series required fenestration. An alternative approach to reduce pleu- ral effusion might be to minimize the use of cardiopulmonary bypass, thereby reducing the activation of inflammatory mediators. ${ }^{6}$ If most of the mediastinal dissection is performed off-pump and no intracardiac procedures are necessary, then the average cardiopulmonary bypass time required for the superior and inferior anastomoses should be considerably decreased.

In this study, no difference in the duration of pleural drainage was noted between the groups. We speculated that peritoneal drainage might be helpful to reduce duration and volume of pleural drainage. Mainwaring, Lamberti, and $\mathrm{Hu}-$ $\mathrm{gli}^{18}$ reported an increase in the concentration of the activated complement C3 and interleukin 6 after the ECFP. Bokesch and colleagues ${ }^{19}$ reported a high concentration of proinflamatory cytokines in the peritoneal fluid. They suggested that peritoneal fluid may serve as a depot for harmful inflammatory cytokines after cardiopulmonary bypass, and removal of the peritoneal fluid could lower serum concentrations.

No difference was observed between the groups with regard to duration of peritoneal drainage and number of patients with prolonged peritoneal drainage; however, the peritoneal fluid drainage volume was higher in group $\mathrm{S}$ than in group L. In addition, cardiopulmonary bypass time was shorter in group $S$ than in group L. No specific reason was found for the prolonged intensive care unit stay of group $\mathrm{S}$ as compared to group L. We speculated that the large volume of peritoneal drainage might require extensive fluid replacement to stabilize hemodynamics. We recognized that the hospital stay was considerably longer than that mentioned in any other previously published reports. Japan's lenient health insurance system might account for this.

This study has several limitations. It is a retrospective and nonrandomized study. There is a lack of reports on peritoneal drainage after the ECFP, and only a few patients in this study were operated on without peritoneal drainage. Therefore, it is very difficult to rule out any influence of peritoneal drainage 
on the postoperative course. In particular, the follow-up period in group $\mathrm{S}$ patients was relatively short inasmuch as they were growing; therefore, the inference regarding freedom from conduit obstruction and the need for reoperation in relation to outgrowth is uncertain. Further, a long-term follow-up study is essential.

In conclusion, we evaluated the technical feasibility of ECFP in patients weighing less than $10 \mathrm{~kg}$. In terms of mortality and midterm results, the outcome of ECFP was acceptable in patients who weighed less than $10 \mathrm{~kg}$. Currently, it may not be possible to consider ECFP as the standard procedure in patients weighing less than $10 \mathrm{~kg}$. However, the procedure may be feasible in patients who, for instance, have severe cyanosis owing to pulmonary arteriovenous malformation. Further studies are required to assess the late hemodynamics of patients with small conduits when they achieve full somatic growth and the long-term outcome of these small conduits.

\section{References}

1. Fontan F, Baudet E. Surgical repair of tricuspid atresia. Thorax. 1971; 26:240-8.

2. Azakie A, McCrindle BW, Van Arsdell G, Benson LN, Coles J, Hamilton R, et al. Extracardiac conduit versus lateral tunnel cavopulmonary connections at a single institution: impact on outcomes. $J$ Thorac Cardiovasc Surg. 2001;122:1219-28.

3. Kumar SP, Rubinstein CS, Simsic JM, Taylor AB, Saul JP, Bradley SM. Lateral tunnel versus extracardiac conduit Fontan procedure: a concurrent comparison. Ann Thorac Surg. 2003;76:1389-96.

4. Fiore AC, Turrentine M, Rodefeld M, Vijay P, Schwartz TL, Virgo KS, et al. Fontan operation: a comparison of lateral tunnel with extracardiac conduit. Ann Thorac Surg. 2007;83:622-9.

5. Marcelletti C, Corno A, Giannico S, Marino B. Inferior vena cavapulmonary artery extracardiac conduit: a new form of right heart bypass. J Thorac Cardiovasc Surg. 1990;100:228-32.

6. Petrossian E, Reddy VM, Collins KK, Culbertson CB, MacDonald MJ, Lamberti JJ, et al. The extracardiac conduit Fontan operation using minimal approach extracorporeal circulation: early and midterm outcomes. $J$ Thorac Cardiovasc Surg. 2006;132:1054-63.

7. de Leval MR, Kilner P, Gewillig M, Bull C. Total cavopulmonary connection: a logical alternative to atriopulmonary connection for complex Fontan operations. Experimental studies and early clinical experience. J Thorac Cardiovasc Surg. 1988;96:682-95.

8. de Leval MR, Dubini G, Migliavacca F, Jalali H, Camporini G, Redington A, et al. Use of computational fluid dynamics in the design of surgical procedures: application to the study of competitive flows in cavo-pulmonary connections. J Thorac Cardiovasc Surg. 1996;111: 502-13.

9. Petrossian E, Thompson LD, Hanley FL. Extracardiac conduit variation of the Fontan procedure. Adv Card Surg. 2000;12:175-98.

10. Sakamoto K, Ikai A, Fujimoto Y, Ota N. Novel surgical approach "intrapulmonary-artery septation" for Fontan candidates with unilateral pulmonary arterial hypoplasia or pulmonary venous obstruction. Interact Cardiovasc Thorac Surg. 2007;6:150-4.

11. Marcelletti CF, Iorio FS, Abella RF. Late results of extracardiac Fontan repair. Semin Thorac Cardiovasc Surg Pediatr Card Surg Annu. 1999;2: $131-42$.

12. Pizarro C, Mroczek T, Gidding SS, Murphy JD, Norwood WI. Fontan completion in infants. Ann Thorac Surg. 2006;81:2243-8.

13. Gaynor JW, Bridges ND, Cohen MI, Mahle WT, Decampli WM, Steven JM, et al. Predictors of outcome after the Fontan operation: is hypoplastic left heart syndrome still a risk factor? J Thorac Cardiovasc Surg. 2002;123:237-45.
14. Hosein RB, Clarke AJ, McGuirk SP, Griselli M, Stumper O, De Giovanni JV, et al. Factors influencing early and late outcome following the Fontan procedure in the current era. The 'Two Commandments'? Eur J Cardiothorac Surg. 2007;31:344-52.

15. Amodeo A, Galletti L, Marianeschi S, Picardo S, Giannico S, Di Renzi P, et al. Extracardiac Fontan operation for complex cardiac anomalies: seven years' experience. J Thorac Cardiovasc Surg. 1997;114: 1020-30.

16. Nakao S, Come PC, McKay RG, Ransil BJ. Effects of positional changes on inferior vena caval size and dynamics and correlations with right-sided cardiac pressure. Am J Cardiol. 1987;59:125-32.

17. Gupta A, Daggett C, Behera S, Ferraro M, Wells W, Starnes V. Risk factors for persistent pleural effusions after the extracardiac Fontan procedure. J Thorac Cardiovasc Surg. 2004;127:1664-9.

18. Mainwaring RD, Lamberti JJ, Hugli TE. Complement activation and cytokine generation after modified Fontan procedure. Ann Thorac Surg. 1998;65:1715-20.

19. Bokesch PM, Kapural MB, Mossad EB, Cavaglia M, Appachi E, Drummond-Webb JJ, et al. Do peritoneal catheters remove pro-inflammatory cytokines after cardiopulmonary bypass in neonates? Ann Thorac Surg. 2000;70:639-43.

\section{Discussion}

Dr Ed Petrossian (Madera, Calif). Dr Ikai, I enjoyed your presentation. I will make a comment on the paper inasmuch as I believe it is an important subject, and I have 3 questions for you. The comment will be primarily focused on the issue of putting in small conduits in small patients.

In this study, you and your colleagues have shown that the ECFP can be performed with excellent perioperative and midterm outcomes in patients less than 2 years of age and less than $10 \mathrm{~kg}$ in weight. At a median follow-up time of 29 months, there were no thromboembolic events and none of the patients required conduit replacement owing to obstruction. I believe this is an important and timely paper because it brings into light the concerns and controversies about the timing of this operation with respect to age, weight, and the related issue of conduit size. Regarding the choice of conduit size, this decision is influenced by two competing factors. The first is the desire to insert a large conduit to avoid growth-related obstruction. Ideally, the conduit should match or slightly exceed the size of an average adult IVC at the level of the diaphragm. The second is the desire to avoid extremes of IVC-conduit mismatch. Significant mismatch can lead to turbulence, energy loss, stasis, and thrombosis. Information on the average size of the adult IVC at the level of the diaphragm is limited. Most studies instead report the size of the infrahepatic or most commonly the infrarenal IVC. Accuracy of the studies is affected by the fact that the IVC is an extremely compliant vessel so that its diameter and shape vary greatly with a number of factors, including patient body position, volume status, systemic venous pressure, phase of respiration, and to a lesser extent phase of the cardiac cycle. In adults, the size of the IVC does not correlate with age, height, weight, or body surface area. Therefore, prediction of a patient's future IVC diameter based on projections of the patient's future height, weight, or body surface area as an adult may be inaccurate.

The most consistent finding of the IVC diameter is that it correlates well with right-sided systemic venous pressures. Patients with elevated pressures have been shown to have significantly dilated IVCs. It therefore follows that an adult patient with a Fontan circulation and an inherently elevated systemic venous pressure will be expected to have a dilated IVC. The available data on IVC diameter 
based on angiography, computed tomographic scan, and echocardiographic studies suggest that the average normal IVC diameter ranges from 20 to $28 \mathrm{~mm}$ with significant interstudy variability. In patients with elevated systemic venous pressures, the average diameter is about $30 \mathrm{~mm}$. These data suggest that most conduits, especially those less than 18 or $20 \mathrm{~mm}$, eventually will need to be replaced. It appears, therefore, that a protocol of using small conduits in patients less than $10 \mathrm{~kg}$ in weight will likely lead to significant conduit obstruction and the need for early reoperation. One option, of course, is to routinely use 20 -mm conduits in these small patients. Although you did not report any case of thromboembolism, we believe that insertion of markedly oversized conduits is not an optimal solution either, inasmuch as it can cause significant IVCconduit size mismatch and related complications.

I have 3 questions for you. First, what size mismatch between the IVC and the conduit are you comfortable with at the time of the operation? In other words, when you are trying to decide what size conduit to insert at the time of the operation, how much larger can the conduit be compared with the size of the IVC?

Dr Ikai. Thank you, Dr Petrossian, for your comments and the question. Size mismatch between the IVC and the conduit may not be so big an issue. We have not measured the size of the IVC during the operation because we can cut the IVC not on the IVC itself. Maybe sometimes we can make the incision line to the right atrium and maybe the IVC tissue has included some right atrial tissue. That means that these tissues are very flexible and sometimes we can put a much larger conduit on that. Maybe a problem has happened with size mismatch between the pulmonary artery to the conduit. Another big issue is if we insert too large a conduit, pulmonary vein obstruction may result. We think that in a baby weighing less than $10 \mathrm{~kg}$, an $18 \mathrm{~mm}$ in diameter conduit is suitable. In a baby less than $20 \mathrm{~kg}$, maybe a $20 \mathrm{~mm}$ in diameter conduit is suitable.

Dr Petrossian. I agree with you. We also use a cuff of atrium to anastomose to the conduit and not the IVC itself so that we can put in a larger conduit, and the conduit is almost always larger than the IVC; however, there is a limit to that. In our experience, and I think this is corroborated by others, we try to avoid upsizing the conduit by more than $25 \%$ compared with the size of the IVC to avoid a sudden change in vessel caliber going from the IVC to the conduit. This discrepancy has been demonstrated to cause a lot of turbulence, energy loss, stasis, and thrombosis.

My second question is, since your patients less than $10 \mathrm{~kg}$ are at risk for outgrowing their conduits, how do you plan on monitoring them? In other words, what diagnostic modalities do you use to look for conduit obstruction as these patients grow?

Dr Ikai. I showed the postoperative angiogram in the presentation. We routinely perform angiography a year after the operation. At that time, if the conduit shows some obstruction, it may be a problem, but so far we have not seen any obstruction on the angiogram. If the patient needs more follow-up, we use a computed tomographic angiogram or a magnetic resonance angiogram because they are less invasive measures.

Dr Petrossian. In our experience with more than 360 Fontan patients, we have been primarily monitoring them with echocardiograms, but I agree with you that as these patients grow and become more at risk for conduit obstruction, more accurate imaging modalities are going to be necessary. Magnetic resonance imaging, computed tomography, and probably also cardiac catheterization may be needed to measure the gradient across these conduits.

My third and last question is, what will be your criteria for reoperation for conduit obstruction in asymptomatic patients? We all agree that symptomatic patients will need conduit replacement, but at what point and with what diagnostic findings will you be comfortable with replacing a conduit in an asymptomatic patient?

Dr Ikai. It is very difficult to change the conduit in an asymptomatic patient. However, if there is a pressure gradient between the IVC and the conduit at catheterization, we may have to do the operation. During catheterization, with the patient in the resting position, the data, the pressure number, may not be accurate, so we probably will have to do an exercise test for these patients and get some exercise tolerance. If these numbers become low, that may indicate that the conduit should be changed.

Dr Petrossian. I agree that exercise testing may be one way to determine when it is time for conduit replacement. Imaging modalities may not be sufficient. These IVCs will eventually dilate because they are very compliant vessels. The fact that they become very large does not necessarily mean that they are obstructed. In addition, collaterals will develop, just as with the SVC, in patients with bidirectional Glenn shunts, so it will be difficult to figure out when it is time to replace the conduit. However, I think if at cardiac catheterization there is any gradient, even a small amount of gradient between the conduit and a dilated IVC in combination with an abnormal exercise test, then it will be time to proceed with conduit replacement even if the patient is asymptomatic.

Dr Ikai. In terms of reoperation, when we started this strategy, we were still thinking about this Fontan procedure as a palliative procedure because we did not have any long-term result with this small conduit. Now, because of the good result of the Fontan conversion from the classic Fontan to the total cavopulmonary connection, we think the operation itself is not so risky, especially in a patient who has an established Fontan circulation.

Dr Petrossian. I certainly I agree with that. When the patients return to have the conduit replaced, it is not as big an operation or as risky as the first primary Fontan.

Dr Winfield Wells (Los Angeles, Calif). My question is pretty simple. Why do this? What are the advantages? Your 2 groups came out the same. The saturations are the same in the longerterm follow-up. They seemed to have the same saturations when you did them, so why not wait? What are the advantages of doing this operation in a patient weighing less than $10 \mathrm{~kg}$ ?

Dr Ikai. We believe that the final goal of the Fontan operation is elimination of cyanosis, and in these 2 groups the big difference is not only the body weight but also the age. We did this operation at around a year of age. If we wait until patients become $15 \mathrm{~kg}$, we may have to wait until the baby becomes 2 or 3 years old. Waiting these 1 or 2 years may not be good for the patient. In these 2 years the patient's activity is increasing. Maybe the child starts walking and running. This quality we think is very important. We want to eliminate cyanosis. That is our reason to do this operation.

Dr Wells. Do you have any evidence for that?

Dr Ikai. We have not published yet, but when we do this operation at the younger age, some children catch up soon. This is another reason to do this operation early. 